\title{
Levosimendan Pretreatment Inhibits Myocardial Apoptosis in Swine after Coronary Microembolization
}

\author{
Jiangyou Wang ${ }^{\mathrm{a}}$ Han Chen ${ }^{\mathrm{b}}$ You Zhou ${ }^{\mathrm{a}}$ Qiang Su${ }^{\mathrm{a}}$ Tao Liu Lang Lia $^{\mathrm{a}}$ \\ aDepartment of Cardiology, the First Affiliated Hospital of Guangxi Medical University, Guangxi \\ Cardiovascular Institute, Nanning, 'bepartment of Cardiac Surgery, Wuhan Asia Heart Hospital, Wuhan, \\ China
}

\section{Key Words}

PTEN • Akt • Caspase 3• Levosimendan • Coronary microembolization • Apoptosis

\begin{abstract}
Background/Aims: In addition to its cardiotonic effect, levosimendan has been thought to have multiple cardiovascular benefits, including anti-inflammatory and anti-apoptotic. Phosphatase and tensin homolog deleted on chromosome ten (PTEN) has been revealed to be up-regulated in circumstances of coronary microembolization (CME), and the PTEN signaling pathway mediates myocardial apoptosis in swine after CME. However, whether this functional protein could be modified by pretreatment of levosimendan in models of CME has not been disclosed yet. Methods: Swine CME was induced by intra-coronary injection of inertia plastic microspheres (diameter $42 \mu \mathrm{m}$ ) into left anterior descending coronary, with or without pretreatment of levosimendan or PTEN siRNA. Echocardiologic measurements, Terminal-deoxynucleotidyl Transferase Mediated Nick End Labeling (TUNEL) staining and western blotting were applied to assess their functional, morphological and molecular effects in CME. Results: PTEN mRNA and protein were aberrantly up-regulated in cardiomyocytes following CME. Furthermore, down-regulation of PTEN in vivo via siRNA was associated with an improved cardiac function, attenuated myocardial apoptosis, and concomitantly inhibited expressions of key proapoptotic proteins such as caspase-3. Interestingly, levosimendan could markedly attenuate PTEN expression and inhibit myocardial apoptosis, therefore partially reverse cardiac dysfunction. Conclusion: Modulation of PTEN was probably as a potential mechanism involved in the beneficial effects of pretreatment of levosimendan to cardiac function and apoptosis in animal models of CME.
\end{abstract}

\section{Introduction}

Coronary microembolization (CME), which can be induced by either a spontaneous rupture of a vulnerable coronary atherosclerotic plaque or therapeutic percutaneous 


\section{Cellular Physiology Cell Physiol Biochem 2017;41:67-78 \begin{tabular}{l|l|l} 
DOI: 10.1159/000455950 & $\begin{array}{l}\text { O 2017 The Author(s). Published by S. Karger AG, Basel } \\
\text { www.karger.com/cpb }\end{array}$
\end{tabular}}

Wang et al.: Levosimendan is Involved in CME-induced Myocardial Apoptosis

coronary interventions, has been found be associated with adverse outcomes such as cardiac contractile dysfunction and reduced coronary reserve [1, 2]. There have been major advances in identifying the factors of the myocardial inflammatory response and apoptosis that are involved in CME-induced myocardial injury [3-8]. However, the overall complexity of myocardial injury suggests that additional regulatory mechanisms remain to be elucidated. Therefore, it is reasonable to propose that interventions which attenuate myocardial apoptosis could be protective for the heart from CME related cardiac dysfunction. Levosimendan has been developed for the treatment of acute heart failure and other cardiac conditions where the use of an inodilator is considered appropriate. At least three major pharmacological actions have been identified [9], i.e. (i) the selective binding to $\mathrm{Ca} 2+$-saturated cardiac troponin $\mathrm{C}$, (ii) the opening of ATP-sensitive potassium (KATP) channels in the vasculature, and (iii) the opening of KATP channels in the mitochondria. The pharmacology of levosimendan includes positive inotropy with energy-sparing effects, positive effects on ventriculo-arterial coupling, peripheral vasodilation and increasing tissue perfusion, anti-stunning effects and anti-inflammatory and anti-apoptotic effects [10]. And, recent studies revealed that the protective effects of levosimendan on ischemia/reperfusion injury and primarily related to the regulation of apoptosis $[11,12]$, although the potential molecular mechanisms remained unclear.

Phosphatase and tensin homolog deleted on chromosome ten (PTEN), a negative regulator of phosphatidylinositol-3 kinase (PI3K)-Akt pathways, has been recently found to be up-regulated in ischemic myocardium and involved in a wide variety of myocardial apoptotic responses [13]. The PTEN/Akt pathway had been involved in the pathogenesis of many cardiovascular diseases such as cardiac hypertrophy, myocardial contractile dysfunction, coronary angiogenesis, heart failure and ischemia-reperfusion injury [14]. In addition, by a series of tests, we have previously shown that the PTEN/Akt signaling pathway contributes to cardiomyocyte apoptosis in swine after CME $[7,15]$. However, whether the protective effects of levosimendan to CME related myocardial apoptosis were related to the regulation of the PTEN/Akt pathway remains to be determined.

\section{Materials and Methods}

\section{Animal preparation}

Healthy swine ( 25 - $30 \mathrm{~kg}$ ) were purchased from the Animal Center of the Agriculture College of Guangxi University (Nanning, People's Republic of China), and throughout all of the experimental stages, the animals were maintained under controlled temperature, humidity, and light conditions, with pig feed and water provided ad libitum. This investigation conforms to the Guide for the Care and Use of Laboratory Animals published by the US National Institute of Health (NIH publication No. 85-23, revised 1996). The Clinical and Animal Research Ethics Committees of Guangxi Medical University approved all of the procedures.

\section{Modeling and Grouping}

The swine were randomly distributed into five groups as follows: the sham surgery group (control, $\mathrm{n}$ = 5), CME group (CME, $n=5$ ), levosimendan pretreatment group (Levo group, $n=5$ ), PTEN siRNA-treated before CME group (PTEN siRNA, $n=5$ ), and control siRNA-treated group (control siRNA, $n=5$ ). The Levo group was pretreated with Levo $24 \mathrm{~h}(0.05 \mu \mathrm{g} / \mathrm{kg} / \mathrm{min})$ and high-loading-dose of Levo $(0.2 \mu \mathrm{g} / \mathrm{kg} / \mathrm{min})$ $60 \mathrm{~min}$ before microsphere injection. The CME model was induced by the manual unremitting injection of microspheres into the left anterior descending (LAD) artery, as previously described by Dorge et al. [4] Breuckmann et al. [16] and Carlsson et al. [17].The swine were initially sedated via an IM injection of a combination of ketamine and atropine (10-15 mg/ kg and $2 \mathrm{mg}$, respectively). After endotracheal intubation, anesthesia was maintained via an intravenous drip of diazepam into the ear vein. The right femoral artery was separated, and a 6F (Cordis, USA) vascular sheath was placed. Prior to the coronary cannulation, the animals were anticoagulated via an intravenous injection of $200 \mathrm{U} / \mathrm{kg}$ heparin followed by $100 \mathrm{U} / \mathrm{kg}$ per h to maintain heparinization. A 6F JL 4.0 guiding catheter was used for the coronary angiography. After the coronary angiography, a 1.8F infusion catheter (Cordis, Inc., USA) was placed into the left anterior descending 


\section{Cellular Physiology Cell Physiol Biochem 2017;41:67-78

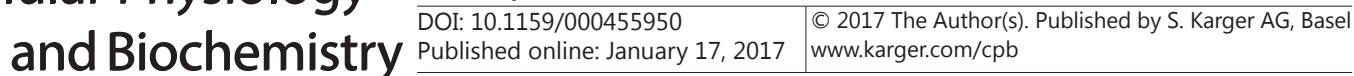 \\ Wang et al.: Levosimendan is Involved in CME-induced Myocardial Apoptosis}

(LAD) artery with the tip located between the second and third diagonal branches. Microspheres with a diameter of $42 \mu \mathrm{m}$ (Dynospheres; Dyno Particles; Lillestrøm, Norway) at a mean dosage of 100,000 were selectively infused into the LAD within $40 \mathrm{~min}$ followed by a flush with $10 \mathrm{ml}$ of saline. The sham-operated swine (sham group) were subjected to the same procedures, except that the injection was saline rather than microspheres. The systemic blood pressure and heart rate were continuously monitored during the procedure.

In vivo PTEN siRNA administration

In vivo transfer was performed according to the method described previously [7]. After coronary angiography, a $1.8 \mathrm{~F}$ infusion catheter (Cordis, Inc. USA) was placed in the LAD artery with the tip located between the second and third diagonal branches. A total of $100 \mu \mathrm{g}$ of PTEN siRNA (Genepharma, PTENsus-368) or control siRNA (Genepharma) was diluted in the same volume of the in vivo transfection reagent (EntransterTM-in vivo; Engreen, Beijing, China). After mixing the solution gently by pipetting up and down, the siRNA solutions were selectively infused into the LAD. Then, $72 \mathrm{~h}$ after the PTEN siRNA or control siRNA administration, CME surgery was performed. In our previous study, we found that the protein level of PTEN was obviously up-regulated at $12 \mathrm{~h}$ post-CME [5], so all of the swine were sacrificed at $12 \mathrm{~h}$ after the CME or sham surgery in this study.

Design, synthesis and transfection of PTEN SiRNA

The PTEN mRNA sequence was found in GenBank (Gene ID: 100156264) and synthesized by GenePharma company (Shanghai, China). The sense strand and the antisense strand of the PTEN siRNA were 5'-GGCGUAUACAGGAACAAUATT-3' and 5'- UAUUGUUCCUGUAUACGCCTT - 3 ', respectively. The control siRNA was purchased from the same company. A total mass of $100 \mu \mathrm{g}$ PTEN siRNA or control siRNA was diluted with $100 \mu \mathrm{l}$ transfection reagent (EntransterTM - in vivo; Engreen, Beijing, China). Mix thoroughly by pipetting the solution up and down. Then the mixture was injected intracoronarily via the $1.8 \mathrm{~F}$ infusion catheter, followed by $2 \mathrm{ml}$ normal saline injection.

\section{Serum c-troponin I measurement}

EDTA-anticoagulated blood samples $(1.0 \mathrm{ml})$ were collected from the femoral artery in each group 12 $\mathrm{h}$ following sham operation or CME and centrifuged at $4000 \mathrm{rpm}$ for $15 \mathrm{~min}$. Serum samples were stored at $-80^{\circ} \mathrm{C}$ for detection. Serum c-troponin I was detected by electro-chemistry method according to the manufacturer's instruction (Roche, Inc, Switzerland).

\section{Echocardiography}

Transthoracic echocardiographic studies were performed by one experienced investigator who was blinded to the study protocol using a GE VIVID 7 system with a 1.5-4.3 MHZ transducer. Left ventricle ejection fraction (LVEF), left ventricle end-diastolic diameter (LVEDd), fractional shortening (FS) and cardiac output (CO) were obtained.

TUNEL assay

Apoptotic cardiomyocytes were detected using the terminal deoxymu-cleotidyl transferase-mediated dUTP nick end-labeling (TUNEL) assay kit (Roche, USA). TUNEL-positive signal was located in nuclei and apoptotic nuclei were stained yellow-brown while the normal cell nuclei light blue. Meanwhile, morphological features of apoptosis (small, condensed nuclei, cell shrinkage and nuclear fragmentation) were taken into consideration. In each section, 10 random high-powered fields (magnification, $\times 400$ ) were observed to count TUNEL-positive cardiomyocyte nuclei and apoptotic index (\%) was calculated as the percentage ratio of TUNEL-positive cell nuclei to the total nuclei.

\section{Real-time quantitative PCR analysis}

Total RNA from a fresh tissue block was extracted using a Trizol Reagent Kit (Gibco, USA), and 4 $\mu \mathrm{g}$ of RNA was reverse-transcribed using a Reverse Transcriptase Kit (Promega, USA) according to the manufacturer's instructions.

Real-time PCR was performed using an ABI PRISM 7000 system (Applied Biosystems, CA, USA) using the non-sequence-specific SYBR Green I dye (TaKaRa, Japan). The reactions included $2 \mu$ of cDNA, primers 


\section{Cellular Physiology Cell Physiol Biochem 2017;41:67-78 \begin{tabular}{l|l|l} 
DOI: 10.1159/000455950 & O 2017 The Author(s). Published by S. Karger AG, Basel \\
www.karger.com/cpb
\end{tabular} \\ Wang et al.: Levosimendan is Involved in CME-induced Myocardial Apoptosis}

( $0.5 \mu \mathrm{l}$ each), and $12.5 \mu \mathrm{l}$ of SYBR Green Master Mix (Applied Biosystems, CA, USA), which binds to any doublestranded DNA, as well as water added to a final volume of $25 \mu \mathrm{l}$. PCR was performed under the following cycling conditions: initial denaturation step at $95^{\circ} \mathrm{C}$ for $10 \mathrm{~min}$, followed by 45 cycles of amplification $\left(95^{\circ} \mathrm{C}\right.$ for $15 \mathrm{~s}$ and $60^{\circ} \mathrm{C}$ for $1 \mathrm{~min}$ ). The primers were 5-GAGCCATTTCCATCCTGCAG-3 and 5-GCTGTCATGTCTGGGAGTCT-3 for swine PTEN and 5-CACCTTCTACAACGAGCTGC-3 and 5-TCATCTTCTCACGGTTGGCT-3 for actin (all primers were designed by TaKaRa, Japan). The transcript expression levels were quantified via the Ct value method, and the $\mathrm{Ct}$ values were normalised to those of actin as an internal control in the same sample. The specificity of the amplified PCR products was confirmed based on the melting curves.

\section{Western blot analysis}

Briefly, myocardial tissues were homogenized, and aliquots of each fraction were used to determine the protein concentration of each sample using a detergent compatible assay. Protein samples $(100 \mu \mathrm{g})$ were loaded onto polyacrylamide gel, electrophoresed, and transferred to a nitrocellulose membrane. The nitrocellulose membranes were then blocked followed by incubation with the primary antibodies overnight at $4^{\circ} \mathrm{C}$. The following primary antibodies were purchased from Abcam: (1) rabbit anti-PTEN, (2) rabbit antiAkt, p-Akt (phosphorylation sites Threonine308), and (3) rabbit anti-cleaved caspase-3. Immunoblots were processed with secondary antibodies (Abcam Biotechnology) for $1 \mathrm{~h}$ at room temperature. Immunoblots were probed and then exposed to X-ray film. The X-ray films were scanned, and the optical density was determined by Bio-Rad image analysis (Bio-Rad, Hercules, CA, USA).

\section{Statistical analysis}

Statistical analyses were performed using SPSS 13.0 statistical software (IBM Corporation, USA). The quantitative data are presented as the mean (SD). Unpaired Student's t-test and ANOVA were used for comparisons between two groups and among multiple groups, respectively, followed by the StudentNewman-Keuls test for the post hoc analysis. The $P<0.05$ level indicated statistical significance.

\section{Results}

\section{Animal groups}

No significant differences in the body weight, blood pressure or heart rate were observed before and after operation among the four groups. However, after intravenous levosimendan pretreated porcine arterial blood pressure decreased significantly (Table 1).

Levosimendan and PTEN siRNA pretreatments improved cardiac function following CME

Results of echocardiographic examination (Table 2) showed that $12 \mathrm{~h}$ after CME modeling, the CME group exhibited significantly decreased cardiac systolic function as

Table 1. Changes of heart rate, blood pressure and body weight before and after levosimendan -pretreatment among the four groups. CME, coronary microembolization; Sham indicates sham group; CME, CME group; Levo group, CME + Levo- pretreatment group. Data are presented as mean \pm SD. ${ }^{\text {a }} P<0.05$ compared with sham; ${ }^{b} P<0.05$ compared with $\mathrm{CME}$; ${ }^{\mathrm{c}} P<$ 0.05 compared with PreLevo- pretreatment. $(\mathrm{N}=5)$

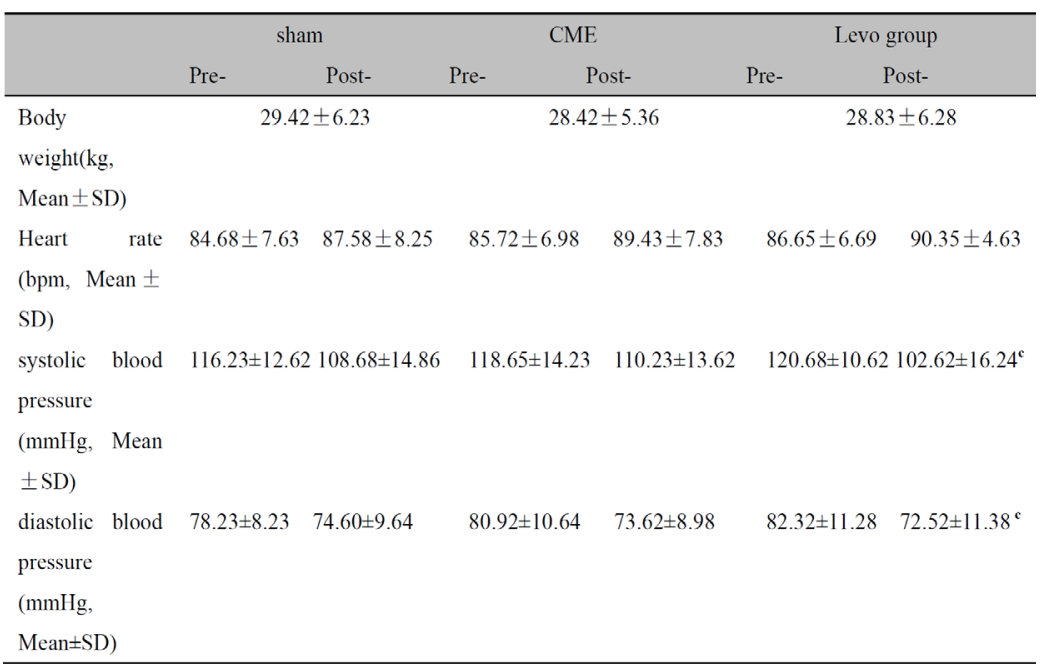




\section{\begin{tabular}{ll} 
Cellular Physiology & Cell Physiol Biochem 2017;41:67-78 \\
\hline DOI: 10.1159/000455950 & 0 2017 The Author(s). Published by S. Karger AG, Basel
\end{tabular}

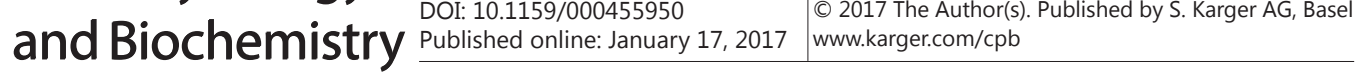 \\ Wang et al.: Levosimendan is Involved in CME-induced Myocardial Apoptosis}

Table 2. Parameters of cardiac function in swine of each group $12 \mathrm{~h}$ after CME modeling: results of the Echocardiologic measurements. CME, coronary microembolization; LVEF, left ventricular ejection fraction; FS, fractional shortening; LVEDd, left ventricular end-diastolic diameter; CO, cardiac output; Levo, levosimendan; PTEN, phosphatase and tensin homolog deleted on chromosome ten. Data are presented as mean \pm SD. ${ }^{a} P<0.05$ compared with sham; ${ }^{b} P<0.05$ compared with CME or control siRNA ( $\left.N=5\right)$

\begin{tabular}{lllll}
\hline Groups & LVEF $(\%)$ & FS $(\%)$ & LVEDd $(\mathrm{mm})$ & CO $(\mathrm{L} / \mathrm{min})$ \\
\hline sham & $68.63 \pm 3.25$ & $42.78 \pm 3.12$ & $32.72 \pm 1.73$ & $4.06 \pm 0.28$ \\
CME & $50.25 \pm 2.89^{\mathrm{a}}$ & $28.62 \pm 2.85^{\mathrm{a}}$ & $38.62 \pm 1.23^{\mathrm{a}}$ & $2.92 \pm 0.29^{\mathrm{a}}$ \\
Levo & $59.76 \pm 3.29^{\mathrm{b}}$ & $35.28 \pm 3.42^{\mathrm{b}}$ & $35.25 \pm 1.52$ & $3.48 \pm 0.34$ \\
PTEN siRNA & $58.28 \pm 4.22^{\mathrm{ab}}$ & $33.25 \pm 3.22^{\mathrm{ab}}$ & $35.85 \pm 1.29$ & $3.42 \pm 0.38^{\mathrm{b}}$ \\
Control siRNA & $49.78 \pm 3.42^{\mathrm{a}}$ & $27.32 \pm 3.63^{\mathrm{a}}$ & $39.26 \pm 1.23^{\mathrm{a}}$ & $2.83 \pm 0.34^{\mathrm{a}}$ \\
\hline
\end{tabular}

Fig. 1. Parameters of cTnI in swine of each group $12 \mathrm{~h}$ after CME modeling: CME, coronary microembolization; Levo, levosimendan; PTEN, phosphatase and tensin homolog deleted on chromosome ten. ${ }^{a} P<0.05$ compared with sham; ${ }^{b} P<0.05$ compared with CME or control siRNA $(\mathrm{N}=5)$.

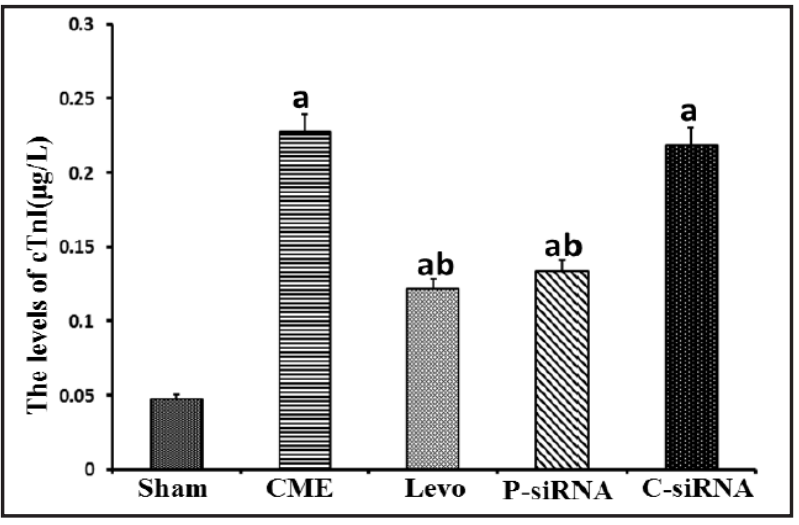

compared with the sham group, as indicated by the significant reduced LVEF, FS and CO, as well as increased LVEDd in CME group $(P<0.05)$. Levosimendan pretreatment improved all indices of cardiac function in CME-treated animals, as reflected by the increased LVEF, FS and CO, as well as decreased LVEDd of the ATV group as compared with the CME group $(P<0.05)$. Similarly, PTEN siRNA pretreatment was also associated with improved cardiac function in CME swine.

Levosimendan and PTEN siRNA pretreatments attenuated mocardial injury following CME

Myocardial injury following CME could be assessed by levels of cTnI in the blood obtained from coronary sinus (Fig. 1). At $12 \mathrm{~h}$ after CME modeling, serum level of cTnI in swine from CME group or control siRNA were higher than controls $(0.228 \pm 0.030 \mu \mathrm{g} / \mathrm{L}$ vs $0.048 \pm 0.008 \mu \mathrm{g} / \mathrm{L}, p<0.05$ ). Moreover, levosimendan pretreatment attenuated myocardial injury following CME, as reflected by the reduced cTnI levels in Levo group compared with CME group $(0.122 \pm 0.022 \mu \mathrm{g} / \mathrm{L}$ vs $0.228 \pm 0.030 \mu \mathrm{g} / \mathrm{L}, p<0.05)$. In addition, PTEN siRNA pretreatment was also associated with reduced cTnI levels $(0.134 \pm 0.014 \mu \mathrm{g} / \mathrm{L})$, which was similar to the effects of levosimendan pretreatment. No significant differences in the levels of cTnI was observed between the CME and Control siRNA groups $(0.228 \pm 0.030 \mu \mathrm{g} / \mathrm{L}$ vs 0.219 $\pm 0.027 \mu \mathrm{g} / \mathrm{L}, p>0.05$ ).

Levosimendan and PTEN siRNA pretreatments decreased myocardial apoptosis following $C M E$

Myocardial apoptosis was assessed using TUNEL staining. Compared with the sham group, more TUNEL-positive (brown) cardiomyocytes could be detected in swine from the CME groups $(P<0.05)$. Interestingly, levosimendan treatment significantly decreased the relative proportion of apoptotic cells following CME $(P<0.05)$. The percentages of myocardial apoptotic cells in the sham, CME, Levo, and control siRNA were $0.24 \pm 0.07,10.56 \pm 2.43$, $6.82 \pm 1.97$ and $11.23 \pm 2.65$ respectively (Fig. 2 ). In addition, PTEN siRNA pretreatment was 


\section{Cellular Physiology \begin{tabular}{ll|l} 
DOI: 10.1159/000455950 & $\begin{array}{l}\text { O 2017 The Author(s). Published by S. Karger AG, Basel } \\
\text { www.karger.com/cpb }\end{array}$
\end{tabular}

Fig. 2. Representative images and quantitative analyses of myocardial apoptosis in minipigs from each group $12 \mathrm{~h}$ post CME modeling: results of the TUNEL staining. a, sham; b, PTEN siRNA; c, CME; d, control siRNA; e, Levo. Normal cell nuclei are stained in pale blue, while the apoptotic cardiomyocyte nuclei (arrows) are stained in brown $(\times 200)$. Results of quantitative analyses indicated that the apoptotic indexes of myocardium were substantially lowered in Levo and PTEN siRNA groups as compared with the CME or the control siRNA groups (fig.2f). ${ }^{\mathrm{a}} p<0.05$ compared with CME or control siRNA. CME, coronary microembolization; Levo, levosimendan; PTEN, phosphatase and tensin homolog deleted on chromosome ten.

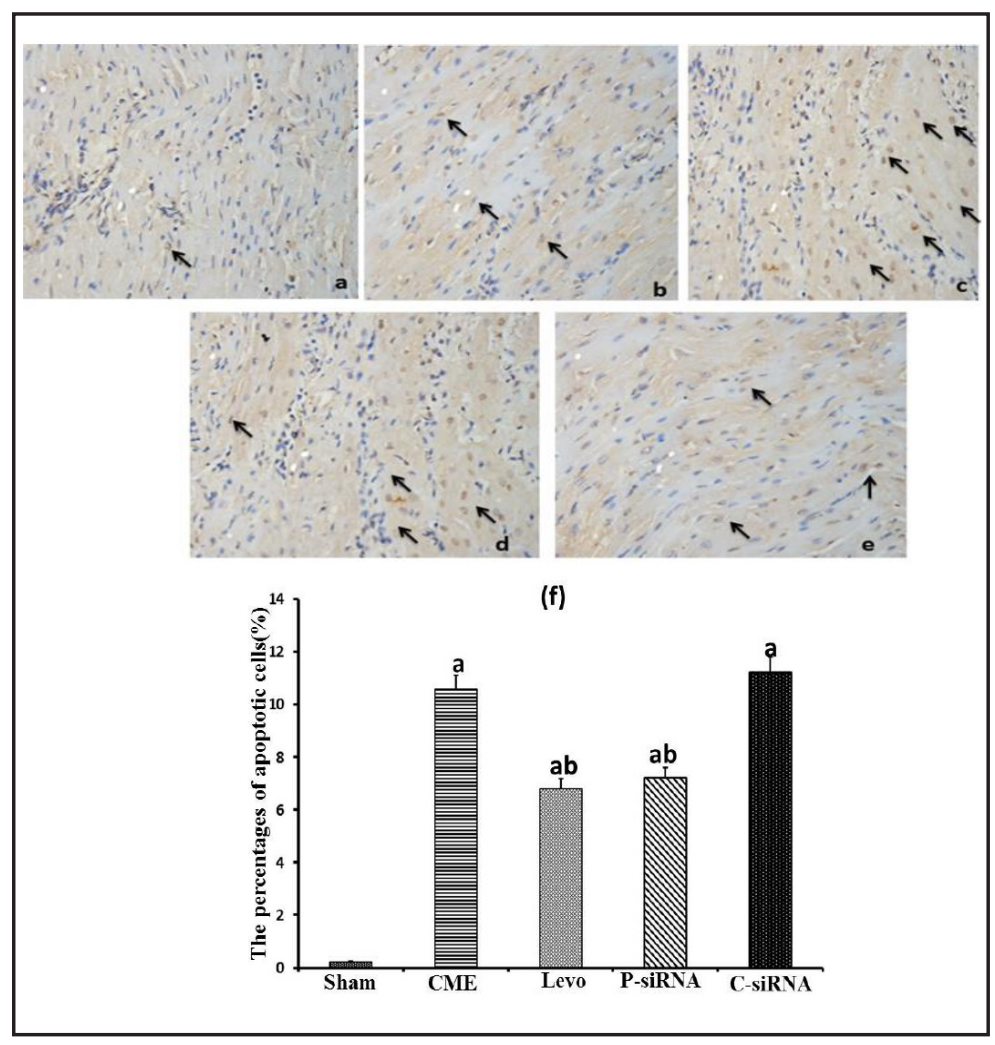

Fig. 3. The PTEN mRNA expression in swine of each group $12 \mathrm{~h}$ after CME modeling: CME, coronary microembolization; Levo, levosimendan; PTEN, phosphatase and tensin homolog deleted on chromosome ten. ${ }^{\text {a }} P<0.05$ compared with sham; ${ }^{b} P<0.05$ compared with CME or control SiRNA $(\mathrm{N}=5)$.

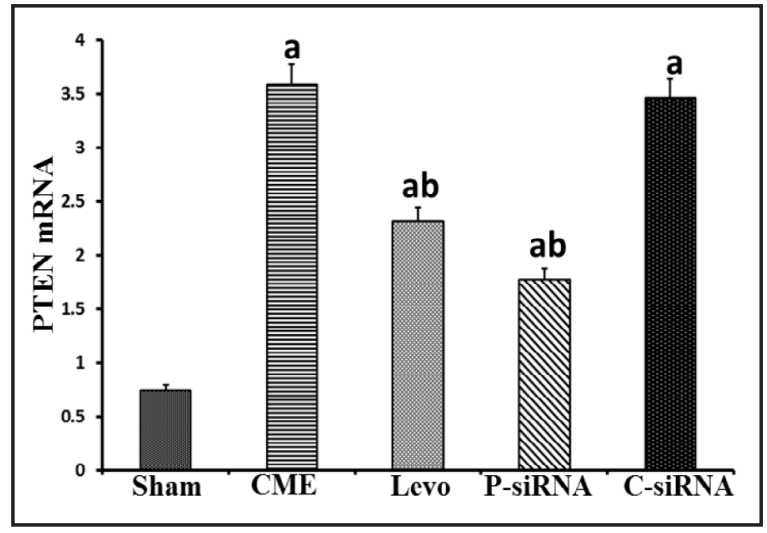

also associated with a decreased myocardial apoptosis $(7.23 \pm 1.85)$, similar to the effects of atorvastatin pretreatment.

The mRNA levels of PTEN each group

The PTEN mRNA expression was significantly higher in the CME and control siRNA groups than in the sham-operated group after surgery $(12 \mathrm{~h}: 3.59 \pm 0.98$ and $3.47 \pm 0.79$ vs. $0.75 \pm 0.15, p<0.05$ ). The administration of PTEN siRNA and levosimendan reduced the mRNA level of PTEN to $1.78 \pm 0.45$ and $2.32 \pm 0.84$ (Fig. 3 ).

PTEN siRNA pretreatment inhibited myocardial Akt signaling in CME swine

Western blotting showed significant up-regulation of PTEN and casepase-3 proteins, as well as a remarkable down-regulation of p-Akt, following CME modeling. Western blot analysis of the infarcted myocardial tissue in each group showed that the expressions of PTEN (Fig. 4A), cleaved caspase-3 (Fig. 4C) were significantly increased in the myocardium of swine from CME groups compared with those from the sham group $(P<0.05)$. However, 
Fig. 4. Coronary microembolization (CME) induces cardiomyocyte apoptosis via the phosphatase and the tensin homolog deleted on chromosometen (PTEN)/Akt signaling pathway. The effects of CME and PTEN small-interfering RNA (siRNA) on the protein levels of PTEN and the Akt pathways as well as caspase 3 in the myocardial tissues in swine 12-hour post-CME modeling are as follows: the results of the Western blotting analyses. The expression levels of PTEN, cleaved caspase- 3 were significantly increased in the CME group compared to those of the sham group $(\mathrm{P}<0.05)$. The expression level of p-Akt (phosphorylation sitesThreonine308) was significantly decreased in the CME group compared to that of the sham group ( $\mathrm{P}<0.05)$. The expression levels of Akt and caspase-3 were not different among the sham, CME, and control siRNA groups. However, PTEN siRNA reduced the levels of PTEN and cleaved caspase-3 and enhanced the level of p-Akt compared to that of the CME group or the control siRNA group. These results indicate that CME induces cardiomyocyte apoptosis via the PTEN/Akt signaling pathway. ${ }^{a} P$ $<0.05$ versus sham; ${ }^{\mathrm{b}} P<0.05$ versus CME or control siRNA. $\mathrm{N}=$ 5 for each group. Sham indicates sham group; CME, CME group; PTEN siRNA, CME + PTEN siRNA group; Control siRNA: CME +Control siRNA group.

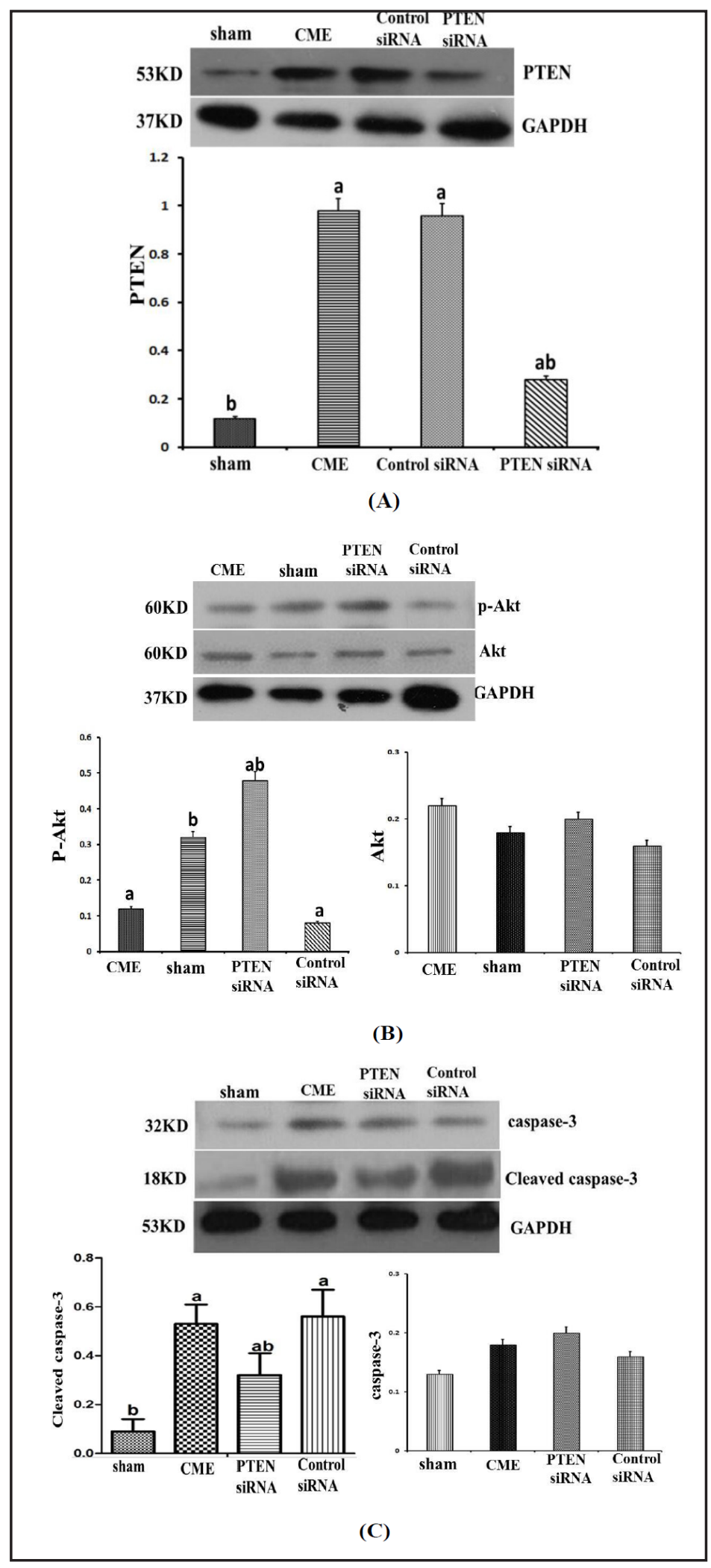

PTEN siRNA pretreatment was associated with reduced levels of PTEN, cleaved caspase-3 proteins, as well as enhanced p-Akt (Fig. 4B) proteins as compared with CME or control siRNA groups $(P<0.05)$. 
Fig. 5. Effects of CME and Levo on the protein levels of PTEN, Akt pathways, caspase 3 in myocardial tissues in minipigs $12 \mathrm{~h}$ post CME modeling: results of western blotting analyses. The expression levels of PTEN (A) and cleaved-caspase-3 (C) were significantly increased in the CME group compared to those of the sham group $(P$ $<0.05$ ). The expression levels of p-Akt (B) was significantly decreased in the CME group compared to those of the sham group $(P<0.05)$. However, administration of levosimendan reduced the levels of PTEN, cleaved-caspase-3 proteins, and enhanced the levels of p-Akt proteins. ${ }^{a} p<$ 0.05 versus sham; ${ }^{b} P<0.05$ versus Levo. CME, coronary microembolization; PTEN, phosphatase and tensin homolog deleted on chromosome ten. Levo, levosimendan.

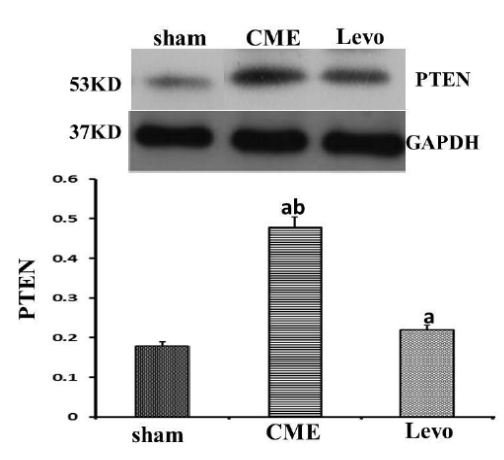

(A)
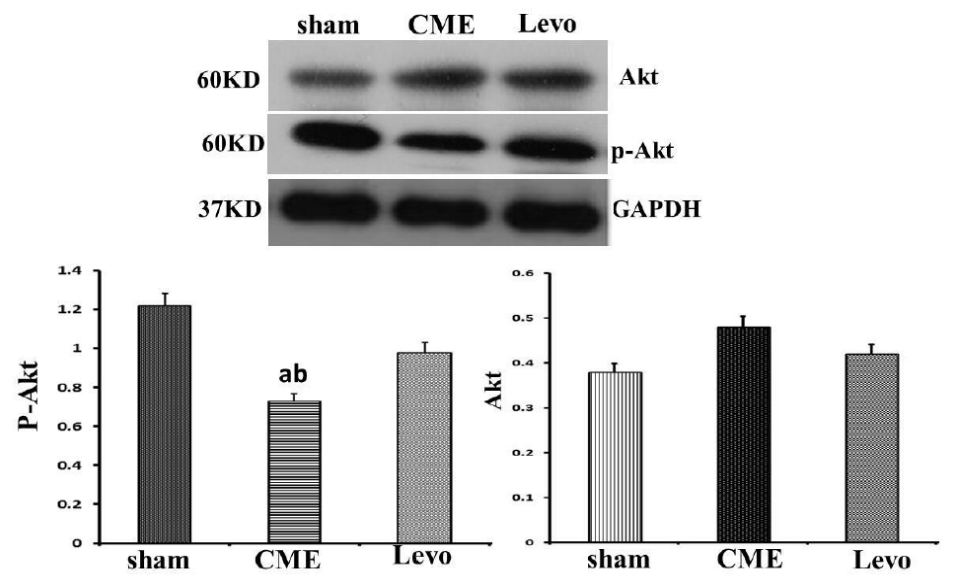

(B)

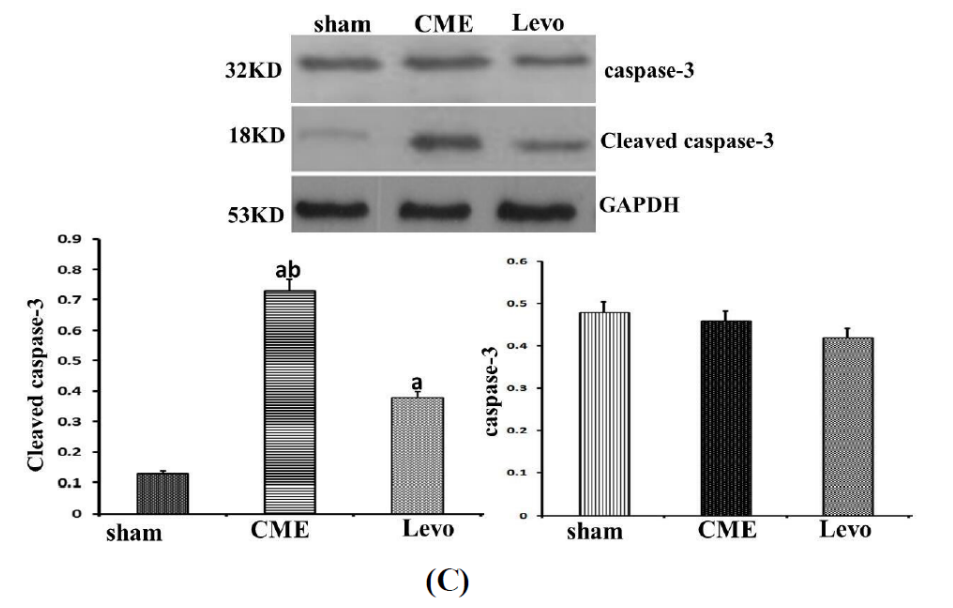

Levosimendan pretreatment inhibited myocardial PTEN/Akt signaling following CME

Western blot analysis of the infarcted myocardium in each group showed that the expressions of PTEN (Fig. 5A), and cleaved caspase-3 (Fig. 5C) were significantly increased in the CME groups as compared with sham groups $(P<0.05)$. However, pretreatment of levosimendan reduced the levels of PTEN (Fig. 5A), cleaved caspase-3 (Fig. 5C) proteins, but enhanced the levels of p-Akt (Fig. 5B) proteins as compared with CME group $(P<0.05)$. Western blot analysis of the infarcted myocardium in each group showed that the expressions of PTEN. Levosimendan could further inhibit the expression of PTEN protein. 


\section{Cellular Physiology and Biochemistry Publishedol $\begin{aligned} & \text { DOI: 10.1159/000455950 } \\ & \text { (c) } 2017 \text { The Author(s). Published by S. Karger AG, Basel } \\ & \text { www.karger.com/cpb }\end{aligned}$ \\ Wang et al.: Levosimendan is Involved in CME-induced Myocardial Apoptosis}

Fig. 6. The molecular cascade after coronary microembolization (CME) CME induced apoptosis via up-regulation of PTEN and reduced Akt and the modulation of other Akt-downstream apoptotic signals, such as caspase-3. After using PTEN siRNA or levosimendan, Akt and other downstream genes were affected, followed by the inhibition of the apoptotic cell death process. CME, coronary microembolization; PTEN, phosphatase and tensin homolog deleted on chromosome ten. Levo, levosimendan.

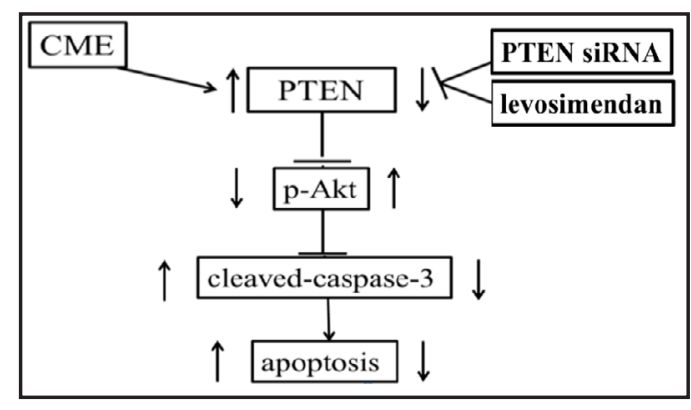

The molecular cascade after CME

CME induced apoptosis via up-regulation of PTEN/Akt and cooperating with other Aktdownstream apoptotic signals, such as caspase-3. After using PTEN siRNA or levosimendan, Akt and other downstream genes were affected, followed by the inhibition of the apoptotic cell death process. Sham: sham group; CME: CME: CME group; PTEN siRNA: CME+ PTEN siRNA group; Control siRNA: CME+ Control siRNA group (Fig. 6).

\section{Discussion}

Several novel findings of present study are summarized as followings. First, we demonstrated that levosimendan pretreatment was associated with attenuated myocardial apoptosis and therefore partially reversed the CME induced myocardial dysfunction. Second, the potential mechanisms underlying the protective effects of levosimendan against CME induced cardiac dysfunction may involve the regulation of PTEN/ Akt signaling pathway. Results of study highlighted the important role of PTEN/Akt in the pathogenesis of CME induced myocardial apoptosis. And, for the first time, our study suggested that levosimendan may attenuate CME induced cardiac dysfunction by modulation of PTEN/Akt pathway and proposed pretreatment of atorvastatin as a potential therapy for CME related cardiac dysfunction.

PTEN is the most common mutation of tumor suppressor gene. It has been recognized that the most important role of PTEN was to regulate normal developmental processes, including cell growth, adhesion, migration, invasion and apoptosis [18]. Recently, it has been showed that PTEN could be detected in vascular endothelial cells, vascular smooth muscle cells, cardiomyocytes and fibroblasts, and it also served as the key regulator of the pathogenesis of a variety of cardiovascular diseases, such as cardiac hypertrophy, myocardial contractile dysfunction, and cardiomyocytes apoptosis, probably by regulating downstream PI3K/Akt pathways $[14,19]$. A variety of cytokines, growth factors and physical stimulation could activate PI3K so as to phosphorylate and activate Akt, which subsequently functions as a key factor in PI3K/Akt cell signaling pathways and downstream effecter of PI3K [20]. Activated Akt may exert its anti-apoptotic effect via regulation of caspase-3 [21]. Although early investigations suggested that activation of PI3K/Akt signaling pathway could effectively inhibit cardiomyocyte apoptosis and reduce the extent of myocardial injury [22]. In addition, by a series of tests, we have previously shown that PTEN/Akt pathway was activated in CME and involved in the pathogenesis of myocardial apoptosis $[7,15]$.

Apoptosis, or programmed cell death, is the highly conserved and physiological process of eliminating cells in multicellular organisms. Apoptosis can be induced by many stimuli and includes the recruitment of caspases, which belong to the family of cysteine proteases. There are two major apoptotic pathways: Upon binding of Fas ligand (FasL) or other ligands to the Fas receptor on the cell surface, the extrinsic pathway involves cleavage of the initiator pro-caspase-8 into the active caspase-8 [23]. The intrinsic pathway is tightly regulated by proteins from the B-cell lymphoma (Bcl)-2 family [24] and targets the mitochondria: Antiapoptotic Bcl-2-like survival factors compete with pro-apoptotic Bax-like death factors [25]. Following the perforation of the outer mitochondrial membrane, cytochrome $\mathrm{C}$ and other 


\section{Cellular Physiology Cell Physiol Biochem 2017;41:67-78 \begin{tabular}{ll|l} 
DOI: 10.1159/000455950 & $\begin{array}{l}\text { O 2017 The Author(s). Published by S. Karger AG, Basel } \\
\text { www.karger.com/cpb }\end{array}$
\end{tabular}}

Wang et al.: Levosimendan is Involved in CME-induced Myocardial Apoptosis

proteins are released into the cytosol [26] resulting in cleavage of the initiator procaspase-9 into the active caspase-9. Ultimately, these two caspase cascades converge in cleaving procaspase-3 into the active effector caspase-3. Caspase-3 is the central apoptotic mediator and can be detected in cellular lysates [27]. Cells undergoing apoptotic death present a typical morphology, consisting of cell shrinking and nuclear fragmentation, which can be quantified in histopathological tissue sections by terminal deoxynucleotidyl transferase-mediated dUTP-biotin nick end labelling (TUNEL) staining [28].

In addition to its cardiotonic effect, levosimendan has been thought to have multiple cardiovascular benefits, including anti-inflammatory and anti-apoptotic. Levosimendan has been developed for the treatment of acute heart failure and other cardiac conditions where the use of an inodilator is considered appropriate. The pharmacology of levosimendan includes positive inotropy with energy-sparing effects, positive effects on ventriculo-arterial coupling, peripheral vasodilation and increasing tissue perfusion, anti-stunning effects and anti-inflammatory and anti-apoptotic effects [9]. Levosimendan has been shown to protect cardiomyocytes from undergoing apoptosis, which depends on ATP-sensitive K+ channels [29]. Notably, in other tissues levosimendan can also show proapoptotic effects [30]. Experimental data focussing on levosimendan and apoptosis are not as abundant as in I/R injury. Pioneering in vitro work by Maytin et al. [10] showed that levosimendan, even at very low concentrations, protected cardiomyocyte from hydrogen peroxide-induced apoptosis by activating mito-chondrial ATP-dependent $\mathrm{K}+$ channels. This effect was counteracted by the $\mathrm{K}+$ channel inhibitor 5-hydroxydecanoid acid. Thus, a solid hypothesis of how levosimendan might influence I/R-induced cardiac apoptosis was provided [29]. Highly interesting in this context, althouth investigated in a considerably different experimental setting, is the observation that levosimendan and dextrosimendan, another simendan, can induce caspasedependent apoptosis (assessed by DNA fragmentation) [30]. The molecular mechanism was mediated by c-Jun NH2-terminal Kinase activation, but not by ATP-dependent K+ channels. In addition, Extracellular signal-Regulated Kinase and p38 Mitogen-Activated Kinase signalling pathways seemed to play no role in its action [30]. In a recently published study, 20 anesthetized (ketamine/pentobarbitone) and ventilated pigs underwent leftsided thoracotomy. The second branch of the LAD was obstructed by a tourniquet resulting in about 50\% reduced poststenotic myocardial systolic shortening. Hypoperfusion was maintained for $4 \mathrm{~h}$. A bolus of $12 \mu \mathrm{g} / \mathrm{kg}$ levosimendan was administered over $15 \mathrm{~min}$ into the LAD proximal of the occluded branch. Levosimendan prevented the down-regulation of anti-apoptotic Bcl-2 and the release of cytochrome $\mathrm{C}$ from the mitochondria into the cytosol resulting in fewer fragmented nuclei in TUNEL staining [31]. In a study performed in anesthetized pigs, intracoronary levosimendan was able to protect heart against I/R by modulation of apoptosis and activation of RISK pathways (ERK1/2 and Akt) [32]. A role for mitoKATP channels and NO has been evidenced [33]. Similar anti-apoptotic effects have been found in liver and kidney, as well [34].

We proved in a previous study that atorvastatin could inhibit myocardial apoptosis in a swine model of coronary microembolization by regulating PTEN/ Akt Signaling Pathway [7]. The potential regulatory effects of PTEN pathways could become a promising treatment strategy for CME related cardiac dysfunction in clinical scenarios. In this study, we found that levosimendan pretreatment could reduce CME-induced myocardial injury through inhibiting myocardial apoptosis with atorvastatin has a similar effect. Moreover, our study suggested again that regulation of PTEN/ Akt pathway seemed to be an important mechanism underlying the cardioprotective effects.

In conclusion, the potential therapeutic role of levosimendan seemed to be related to its regulatory effects on PTEN/ Akt pathway. However, it should be aware that our researches were performed in swine models and the findings may not be extrapolated directly to humans. Therefore, further researches, especially the translational research in humans are needed to evaluate whether the potential regulatory effects of levosimendan on PTEN pathways could become a promising treatment strategy for CME related cardiac dysfunction in clinical scenarios. 


\section{Cellular Physiology Cell Physiol Biochem 2017;41:67-78 \begin{tabular}{l|l} 
DOI: 10.1159/000455950 & O 2017 The Author(s). Published by S. Karger AG, Basel \\
www.karger.com/cpb
\end{tabular}}

Wang et al.: Levosimendan is Involved in CME-induced Myocardial Apoptosis

\section{Acknowledgements}

This study was supported by a grant from National Natural Science Foundation of China (Grant No. 81260042).

\section{Disclosure Statement}

The authors declare no conflicts of interest.

\section{References}

1 Heusch G, Kleinbongard P, Bose D, Levkau B, Haude M, Schulz R, Erbel R: Coronary microembolization: from bedside to bench and back to bedside. Circulation 2009;120:1822-1836.

2 Skyschally A, Schulz R, Erbel R, Heusch G: Reduced coronary and inotropic reserves with coronary microembolization. Am J Physiol Heart Circ Physiol 2002;282:H611-614.

- 3 Dorge H, Schulz R, Belosjorow S, Post H, van de Sand A, Konietzka I, Frede S, Hartung T, Vinten-Johansen J, Youker KA, Entman ML, Erbel R, Heusch G: Coronary microembolization: the role of TNF-alpha in contractile dysfunction. J Mol Cell Cardiol 2002;34:51-62.

4 Dorge H, Neumann T, Behrends M, Skyschally A, Schulz R, Kasper C, Erbel R, Heusch G: Perfusioncontraction mismatch with coronary microvascular obstruction: role of inflammation. Am J Physiol Heart Circ Physiol 2000;279:H2587-2592.

5 Wang J, Li L, Su Q Zhou Y, Chen H, Ma G, Liu T, Tang Z, Liu Y: The involvement of phosphatase and tensin homolog deleted on chromosome ten (PTEN) in the regulation of inflammation following coronary microembolization. Cell Physiol Biochem 2014;33:1963-1974.

-6 Su Q Li L, Zhou Y, Wang J, Liu Y, Ma G: Induction of myocardial PDCD4 in coronary microembolizationrelated cardiac dysfunction: evidence from a large-animal study. Cell Physiol Biochem 2014;34:533-542.

7 Wang J, Chen H, Zhou Y, Su Q, Liu T, Wang XT, Li L: Atorvastatin Inhibits Myocardial Apoptosis in a Swine Model of Coronary Microembolization by Regulating PTEN/PI3K/Akt Signaling Pathway. Cell Physiol Biochem 2016;38:207-219.

8 Wang JY, Chen H, Su X, Zhou Y, Li L: Atorvastatin Pretreatment Inhibits Myocardial Inflammation and Apoptosis in Swine After Coronary Microembolization. J Cardiovasc Pharmacol Ther 2016;pii:1074248416662348.

-9 Papp Z, Edes I, Fruhwald S, De Hert SG, Salmenpera M, Leppikangas H, Mebazaa A, Landoni G, Grossini E, Caimmi P, Morelli A, Guarracino F, Schwinger RH, Meyer S, Algotsson L, Wikstrom BG, Jorgensen K, Filippatos G, Parissis JT, Gonzalez MJ, Parkhomenko A, Yilmaz MB, Kivikko M, Pollesello P, Follath F: Levosimendan: molecular mechanisms and clinical implications: consensus of experts on the mechanisms of action of levosimendan. Int J Cardiol 2012;159:82-87.

$\longrightarrow 10$ Maytin M, Colucci WS: Cardioprotection: a new paradigm in the management of acute heart failure syndromes. Am J Cardiol 2005;96:26G-31G.

-11 Grossini E, Pollesello P, Bellofatto K, Sigaudo L, Farruggio S, Origlia V, Mombello C, Mary DA, Valente G, Vacca G: Protective effects elicited by levosimendan against liver ischemia/reperfusion injury in anesthetized rats. Liver Transpl 2014;20:361-375.

12 Grossini E, Molinari C, Pollesello P, Bellomo G, Valente G, Mary D, Vacca G, Caimmi P: Levosimendan protection against kidney ischemia/reperfusion injuries in anesthetized pigs. J Pharmacol Exp Ther 2012;342:376-388.

13 Latronico MV, Costinean S, Lavitrano ML, Peschle C, Condorelli G: Regulation of cell size and contractile function by AKT in cardiomyocytes. Ann N Y Acad Sci 2004;1015:250-260.

14 Oudit GY, Penninger JM: Cardiac regulation by phosphoinositide 3-kinases and PTEN. Cardiovasc Res 2009;82:250-260.

15 Wang J, Chen H, Su Q, Zhou Y, Liu T, Li L: The PTEN/Akt Signaling Pathway Mediates Myocardial Apoptosis in Swine After Coronary Microembolization. J Cardiovasc Pharmacol Ther 2016;21:471-477. 


\section{Cellular Physiology Cell Physiol Biochem 2017;41:67-78 \begin{tabular}{l|l|l} 
DOI: 10.1159/000455950 & O 2017 The Author(s). Published by S. Karger AG, Basel \\
www.karger.com/cpb
\end{tabular} \\ Wang et al.: Levosimendan is Involved in CME-induced Myocardial Apoptosis}

16 Breuckmann F, Nassenstein K, Bucher C, Konietzka I, Kaiser G, Konorza T, Naber C, Skyschally A, Gres P, Heusch G, Erbel R, Barkhausen J: Systematic analysis of functional and structural changes after coronary microembolization: a cardiac magnetic resonance imaging study. JACC Cardiovasc Imaging 2009;2:121130.

17 Carlsson M, Wilson M, Martin AJ, Saeed M: Myocardial microinfarction after coronary microembolization in swine: MR imaging characterization. Radiology 2009;250:703-713.

18 Yamada KM, Araki M: Tumor suppressor PTEN: modulator of cell signaling, growth, migration and apoptosis. J Cell Sci 2001;114:2375-2382.

19 Oudit GY, Sun H, Kerfant BG, Crackower MA, Penninger JM, Backx PH: The role of phosphoinositide-3 kinase and PTEN in cardiovascular physiology and disease. J Mol Cell Cardiol 2004;37:449-471.

20 De Luca A, Maiello MR, D'Alessio A, Pergameno M, Normanno N: The RAS/RAF/MEK/ERK and the PI3K/ AKT signalling pathways: role in cancer pathogenesis and implications for therapeutic approaches. Expert Opin Ther Targets 2012;16:S17-27.

21 Torella D, Rota M, Nurzynska D, Musso E, Monsen A, Shiraishi I, Zias E, Walsh K, Rosenzweig A, Sussman MA, Urbanek K, Nadal-Ginard B, Kajstura J, Anversa P, Leri A: Cardiac stem cell and myocyte aging, heart failure, and insulin-like growth factor-1 overexpression. Circ Res 2004;94:514-524.

22 Wang Z, Zhang H, Xu X, Shi H, Yu X, Wang X, Yan Y, Fu X, Hu H, Li X, Xiao J: bFGF inhibits ER stress induced by ischemic oxidative injury via activation of the PI3K/Akt and ERK1/2 pathways. Toxicol Lett 2012;212:137-146.

23 Krammer PH: CD95's deadly mission in the immune system. Nature 2000;407:789-795.

24 Wang X: The expanding role of mitochondria in apoptosis. Genes Dev 2001;15:2922-2933.

25 Borner C: The Bcl-2 protein family: sensors and checkpoints for life-or-death decisions. Mol Immunol 2003;39:615-647.

-26 Patterson SD, Spahr CS, Daugas E, Susin SA, Irinopoulou T, Koehler C, Kroemer G: Mass spectrometric identification of proteins released from mitochondria undergoing permeability transition. Cell Death Differ 2000;7:137-144.

27 Scheiermann P, Ahluwalia D, Hoegl S, Dolfen A, Revermann M, Zwissler B, Muhl H, Boost KA, Hofstetter C: Effects of intravenous and inhaled levosimendan in severe rodent sepsis. Intensive Care Med 2009;35:1412-1419.

28 Gavrieli Y, Sherman Y, Ben-Sasson SA: Identification of programmed cell death in situ via specific labeling of nuclear DNA fragmentation. J Cell Biol 1992;119:493-501.

29 Maytin M, Colucci WS: Cardioprotection: a new paradigm in the management of acute heart failure syndromes. Am J Cardiol 2005;96:26G-31G.

-30 Kankaanranta H, Zhang X, Tumelius R, Ruotsalainen M, Haikala H, Nissinen E, Moilanen E: Antieosinophilic activity of simendans. J Pharmacol Exp Ther 2007;323:31-38.

31 Grossini E, Caimmi PP, Platini F, Molinari C, Uberti F, Cattaneo M, Valente G, Mary DA, Vacca G, Tessitore L: Modulation of programmed forms of cell death by intracoronary levosimendan during regional myocardial ischemia in anesthetized pigs. Cardiovasc Drugs Ther 2010;24:5-15.

-32 Caimmi PP, Molinari C, Uberti F, Micalizzi E, Valente G, Mary DA, Vacca G, Grossini E: Intracoronary levosimendan prevents myocardial ischemic damages and activates survival signaling through ATPsensitive potassium channel and nitric oxide. Eur J Cardiothorac Surg 2011;39:e59-67.

-33 Uberti F, Caimmi PP, Molinari C, Mary D, Vacca G, Grossini E: Levosimendan modulates programmed forms of cell death through K(ATP) channels and nitric oxide. J Cardiovasc Pharmacol 2011;57:246-258.

-34 Tsao CM, Li KY, Chen SJ, Ka SM, Liaw WJ, Huang HC, Wu CC: Levosimendan attenuates multiple organ injury and improves survival in peritonitis-induced septic shock: studies in a rat model. Crit Care 2014;18:652. 